\title{
Research Article \\ Effects of the Representation of Convection on the Modelling of Hurricane Tomas (2010)
}

\author{
Irene Marras, Elisabetta Fiori, Lauro Rossi, and Antonio Parodi \\ CIMA Research Foundation, Savona, Italy \\ Correspondence should be addressed to Antonio Parodi; antonio.parodi@cimafoundation.org
}

Received 11 February 2017; Revised 4 May 2017; Accepted 15 May 2017; Published 26 July 2017

Academic Editor: Olivier P. Prat

Copyright (C) 2017 Irene Marras et al. This is an open access article distributed under the Creative Commons Attribution License, which permits unrestricted use, distribution, and reproduction in any medium, provided the original work is properly cited.

\begin{abstract}
The cumulus parameterization is widely recognised as a crucial factor in tropical meteorology: this paper intends to shed further light on the effects of convection parameterization on tropical cyclones' numerical predictions in the "grey zone" (10-1 km grid spacing). Ten experiments are devised by combining five different convection treatments over the innermost, $5 \mathrm{~km}$ grid spacing, domain, and two different global circulation model datasets (IFS and ERA-Interim). All ten experiments are finally analysed and compared to observations provided by the National Hurricane Center's best track record and multisatellite rainfall measurements. Results manifestly point to the superiority of employing no convective parameterization at the scale of $5 \mathrm{~km}$ versus the usage of any of those provided by WRF to reproduce the case study of Hurricane Tomas, which hit the Lesser Antilles and Greater Antilles in late October and early November 2010.
\end{abstract}

\section{Introduction}

Tropical cyclones' (TCs) numerical predictive ability has improved in recent decades thanks to a deeper understanding of the physical mechanisms responsible for the tropical cyclogenesis and subsequent spatiotemporal evolution of these deep moist convective structures and also thanks to the improvement in supercomputing capabilities, which make it possible now to simulate TC at very high resolutions $[1,2]$.

Several studies [3-6] have explored the Weather Research and Forecasting (WRF) model predictive ability sensitivity to its different physical parameterizations, that is, to the effects of varying the computational horizontal and vertical resolutions and the number of domains.

Davis et al. [3] performed, with Advanced Research Hurricane (AHW) component of WRF model, a very comprehensive study of the effects of increased horizontal resolution on hurricane wind forecasts: they compared the accuracy of hurricane track, intensity, and structure in a set of 69 forecasts performed at each of two horizontal grid increments with the AHW-WRF model. These forecasts covered 10 Atlantic tropical cyclones: 6 from the 2005 season and 4 from 2007. The forecasts were integrated from identical initial conditions produced by a cycling ensemble Kalman filter [7]. The highresolution forecasts used moving, storm-centred nests of $4 \mathrm{~km}$ grid spacing and $1.33 \mathrm{~km}$ grid spacing, with explicit convection. The coarse-resolution forecasts consisted of a single $12 \mathrm{~km}$ domain, with Kain-Fritsch cumulus parameterization. The number of vertical levels was 35, and the adopted PBL scheme was YSU (Yonsei University), while the microphysics one was WSM5 [8]. In a nutshell, storm position errors showed no statistically meaningful differences between the coarse-resolution and high-resolution simulations, while storm intensity, defined as the maximum instantaneous $10 \mathrm{~m}$ wind in the model, was slightly better forecast in the nested simulations than in the $12 \mathrm{~km}$ forecasts.

In a study of the sensitivity in simulations of TC Jal (2010) to WRF physics parameterizations, Chandrasekar and Balaji [4] used a setup of 3 domains of 90,30 , and $10 \mathrm{~km}$ of horizontal resolution, respectively, with the scope of determining the best combination of physics schemes for track and intensity forecasts. They showed that their best set of physics combination worked properly for track prediction but variably for predicted cyclone intensity, with the cumulus parameterization having more impact on intensity prediction than any of the other physics subgrid schemes, whereas for 
both track and intensity prediction skill, it was the cumulus together with the PBL and microphysics parameterizations that played a larger role than the other physics schemes (land surface and radiation) of the model.

Concerning the vertical grid resolution (VGR) sensitivity, Zhang et al. [6] performed more than 60 five-day numerical simulations of two different idealized hurricane vortices, and they varied the VGR in different portions of the atmosphere with the operational version of the HWRF model. Their results provided some important hints for designing appropriate VGRs to predict reasonably hurricane intensity and inner-core structures under different environmental flows: certain minimum VGRs (around 40) should be configured to produce reliable intensity forecasts with more detailed innercore structures; relatively higher (lower) VGRs in the lower (middle) levels appear to be more preferable than higher VGRs in the upper levels.

Notably Biswas et al. [5] explored the sensitivity of tropical cyclone track and intensity forecasts to different convective schemes by using the Hurricane Weather Research and Forecasting (HWRF) system. The HWRF configuration similar to the 2012 operational system was used in this study: the parent, middle, and the inner domains have 27, 9, and $3 \mathrm{~km}$ horizontal grid spacing, respectively. A control configuration adopting the HWRF Simplified Arakawa Scheme (SAS) was compared with the Kain-Fritsch and Tiedtke schemes, as well as with newer implementation of the SAS. Averaging over almost 250 cases, they showed that the SAS scheme produced the best track forecasts (Figure 1 of [5]) till a lead time of 72-84 hours followed very closely by KainFritsch scheme.

On average, hurricane track forecasts have improved much faster than the prediction of their intensity [10-12]. Such a challenge is strictly connected to the ability of a model to represent the dynamic processes of a TC, which means recognising the role played by the physical parameterizations as a major critical and limiting factor in numerical weather prediction models. Some studies prove that TCs prediction is very sensitive to the choice of the cumulus scheme [13-15]. Other studies say that the explicit treatment of convection provides instead a more realistic representation of the hurricane, eye and eyewall structure, and storm intensity $[5,16]$.

In this study, the fully compressible and nonhydrostatic Weather and Research Forecasting (WRF) model (version 3.4) (Skamarock et al. 2015) is used to analyse the sensitivity of different convective parameterizations to the prediction of Hurricane Tomas, which occurred in late October and early November of 2010 in the Caribbean Sea.

Hurricane Tomas represents an interesting case study. First of all, it was responsible for a total of 71 deaths in the Lesser Antilles and Greater Antilles, with economic damage in the order of 750 million USD [9].

Secondly, it was the latest hurricane on record (1851-2014) in the calendar year to strike the Windward Islands; thirdly, Tomas was also the fourth-longest lived post-October 28 tropical cyclone in the period of 1945-2015.

Furthermore, the intensity of Tomas was poorly handled in the NHC forecasts; official forecast intensity errors were greater than the mean official errors for the previous 5-year period at all forecast intervals and considerably greater at 48 through $120 \mathrm{~h}$ [9].

Finally, Hurricane Tomas experienced also a rapid intensification (http://www.nhc.noaa.gov/aboutgloss.shtml) phenomenon [17] with an increase in the maximum sustained winds of $30 \mathrm{kt}$ in the period from 0600 UTC on 4 November (40 kt) to 0600UTC on 5 November $(70 \mathrm{kt})$. Furthermore, Atlantic basin hurricane activity in 2010 was quite high due to the combination of anomalously warm sea surface temperatures and a rapidly developing La Niña event. Such situation led to favourable dynamic and thermodynamic conditions for tropical cyclogenesis and intensification.

The layout of the rest of the paper is as follows: Section 2 describes the case study and Section 3 provides an overview of the model setup, while Section 4 presents the study's results. Conclusions are drawn in Section 5.

\section{Description of the Case Study: Hurricane Tomas}

Tomas was the latest hurricane of the 2010 Atlantic hurricane season, bringing floods and landslides to Haiti [18].

As thoroughly described in Pasch and Kimberlain [9], Hurricane Tomas formed from a tropical wave that moved off the coast of West Africa on October 24. Organised convective activity first showed up on 26 October and gradually evolved until around 06UTC on 29 October, when the system transitioned to a tropical depression with a minimum central sea level pressure (SLP) of $1006 \mathrm{hPa}$ located about 740 kilometers southeast of Barbados. Around 12UTC on 29 October, moving west-northwestwards, the system continued to intensify and to strengthen, becoming a tropical storm due to an enhanced upper-tropospheric outflow. After the disturbance slowly approached the Windward Islands, it headed west-northwest and around 09UTC on 30 October the $997 \mathrm{hPa}$ centre was located over the southern coast of Barbados.

Around 12UTC on 30 October, Tomas became a category 1 hurricane on the Saffir-Simpson scale, and around 20UTC the intense northern eyewall passed over St. Lucia reaching its peak intensity of $155 \mathrm{~km} / \mathrm{h}$. Later that day, Tomas became further organised and intensified to category 2 with winds of $160 \mathrm{~km} / \mathrm{h}$ and minimum central pressure of $983 \mathrm{hPa}$. After crossing the Windward Islands, the hurricane weakened to tropical storm force by 00UTC on 1 November due to the impact of a moderate southwesterly shear and dry air intrusion at mid-levels that caused convection to wane near the centre. Between 00UTC on 1 November and 00UTC on 3 November, Tomas became increasingly disorganised with an elongated, tilted circulation that degenerated to a tropical depression with a minimum pressure of $1006 \mathrm{hPa}$ while travelling westwards over the central Caribbean Sea, heavily affected on its west by shear and dry air. Tomas then reintensified to tropical storm strength around 18UTC on 3 November, featuring better organised deep convection and low-level circulation, and by 06UTC on 4 November the storm became stronger and attained hurricane status around 06UTC on 5 November through a rapid intensification 
TABLE 1: Observed data of position, minimum SLP, and maximum surface wind for Hurricane Tomas.

\begin{tabular}{|c|c|c|c|c|c|}
\hline Date & Latitude & Longitude & Pressure (mbar) & Wind speed (knot) & Stage \\
\hline $30 / 0000$ & 11.9 & -57.8 & 999 & 55 & II \\
\hline $30 / 0600$ & 12.7 & -58.9 & 997 & 60 & "I \\
\hline $30 / 0900$ & 13.0 & -59.5 & 997 & 60 & 'I \\
\hline $30 / 1200$ & 13.1 & -60.1 & 993 & 65 & Hurricane \\
\hline $30 / 1800$ & 13.3 & -61.0 & 990 & 80 & "I \\
\hline $30 / 2000$ & 13.4 & -61.2 & 987 & 85 & "I \\
\hline $31 / 0000$ & 13.5 & -61.7 & 982 & 85 & "I \\
\hline $31 / 0600$ & 13.8 & -62.4 & 983 & 85 & $\prime \prime$ \\
\hline $31 / 1200$ & 14.0 & -63.3 & 988 & 80 & "I \\
\hline $31 / 1800$ & 14.2 & -64.4 & 994 & 65 & 'I \\
\hline $01 / 0000$ & 14.1 & -65.8 & 997 & 55 & Tropical storm \\
\hline $01 / 0600$ & 13.9 & -67.1 & 1003 & 45 & $\prime \prime$ \\
\hline $01 / 1200$ & 13.6 & -68.2 & 1005 & 40 & 'I \\
\hline $01 / 1800$ & 13.5 & -69.2 & 1005 & 40 & $\prime \prime$ \\
\hline $02 / 0000$ & 13.5 & -70.3 & 1005 & 40 & "I \\
\hline $02 / 0600$ & 13.5 & -71.4 & 1003 & 45 & "I \\
\hline $02 / 1200$ & 13.5 & -72.5 & 1004 & 40 & "I \\
\hline $02 / 1800$ & 13.6 & -73.4 & 1006 & 35 & $\prime \prime$ \\
\hline 03/0000 & 13.8 & -73.9 & 1006 & 30 & Tropical depression \\
\hline $03 / 0600$ & 14.0 & -74.3 & 1006 & 30 & "I \\
\hline $03 / 1200$ & 14.3 & -74.7 & 1006 & 30 & 'I \\
\hline $03 / 1800$ & 14.7 & -75.1 & 1004 & 35 & Tropical storm \\
\hline $04 / 0000$ & 15.1 & -75.5 & 1003 & 40 & 'I \\
\hline $04 / 0600$ & 15.5 & -75.9 & 998 & 40 & $\prime \prime$ \\
\hline $04 / 1200$ & 15.9 & -76.2 & 996 & 45 & "I \\
\hline $04 / 1800$ & 16.4 & -76.2 & 995 & 50 & $\prime \prime$ \\
\hline $05 / 0000$ & 17.0 & -75.7 & 989 & 60 & $\prime \prime$ \\
\hline $05 / 0600$ & 17.7 & -75.2 & 985 & 70 & Hurricane \\
\hline $05 / 1200$ & 18.7 & -74.7 & 987 & 75 & $\prime \prime$ \\
\hline $05 / 1800$ & 19.7 & -74.0 & 992 & 70 & "I \\
\hline $06 / 0000$ & 20.4 & -73.1 & 995 & 60 & Tropical storm \\
\hline
\end{tabular}

process, after it turned northward to northeastward ahead of an unusually deep mid-tropospheric trough.

Later on the same day, the category 1 hurricane moved along the Jamaica Channel, about $60 \mathrm{~km}$ west-southwest of the western tip of Haiti, and then through the Windward Passage up to the early hours of 6 November when it weakened once again to a tropical storm because of the increasing vertical wind shear. The constant increase in vertical shear and an intrusion of very dry air caused Tomas to downgrade into an extratropical disturbance around the initial hours of 8 November. Best track data are provided in Table 1.

\section{Model Setup}

The fully compressible and nonhydrostatic Weather Research and Forecasting (WRF) model (version 3.4) [19] is used for this work.

The two adopted domains cover a region including Cuba and Haiti as shown in Figure 1: the outer (the blue area) and

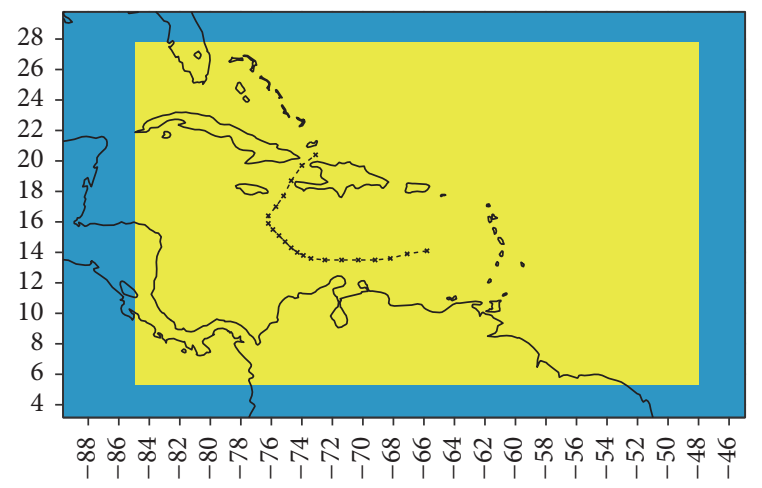

FIGURE 1: The parent ( $15 \mathrm{~km}$ grid spacing) and inner $(5 \mathrm{~km}$ grid spacing) domains used in the numerical experiments with WRFARW model are depicted in blue and yellow, respectively. The best track (i.e., the observed one) of Hurricane Tomas [9] for the period from 00UTC on 1 November to 00UTC on 6 November 2010 is represented by black crosses. 
inner (the yellow area) domain horizontal resolutions are, respectively, 15 and $5 \mathrm{~km}$. The analyses presented in this paper refer to the results of the nested domain, constituted by a grid of 786 by 504 points. Both domains have 41 vertical layers with a higher concentration (about ten) of them in the PBL, in agreement with the recommendations of Zhang et al. [6] about VGRs.

The innermost domain's grid spacing, $5 \mathrm{~km}$, was chosen as a good compromise between computational constraints and recent research results $[1,20]$, which suggest that increasing the horizontal resolution down in the cloud-permitting range $(5-1 \mathrm{~km})$ does not necessarily lead to an actual improvement of the predictive ability of a storm's spatiotemporal evolution, while further exploring the sensitivity to other model features, such as the physical parameterizations, in particular the convective ones, and initial and boundary conditions, can be of great value [1].

On the basis of such considerations, five different approaches to the convection treatment in the innermost domain are considered: varying the cumulus parameterization among four of those available in WRF on one hand and adopting an explicit (no scheme) convection setup on the other hand.

The first convection closure selected has been the KainFritsch (KF, [21]) scheme, which is based on the evaluation of the entrainment and detrainment rate in relation to the local environment profile [22]. The second one has been the BettsMiller-Janjic (BMJ, $[23,24])$ scheme, which is shown to work well in tropical regions [13]. The third scheme chosen has been the Grell-Devenyi (GD, [25]) scheme, which includes an ensemble cumulus scheme in which multiple mass-flux type cumulus schemes with different updraft, downdraft, entrainment, and detrainment parameters and precipitation efficiencies are run within each grid box and then the results are averaged to give feedback to the model [13]. Finally, the last scheme employed is the new Grell ensemble (NGE), similar to the Grell-Devenyi scheme but more suitable for higherresolution domains, allowing for subsidence in neighboring columns and without the quasi-equilibrium approach among the ensemble members [26].

The fifth approach has been to employ the KF scheme in the outer domain, as one of the reference cumulus schemes for hurricane modelling $[3,5]$, and then none in the inner domain so as to treat convection explicitly in that scale. Such choice arises from some studies $[5,16]$ that underline that grid spacing between 8 and $4 \mathrm{~km}$ resolves adequately the TC circulation with explicit convection treatment.

Among the several microphysics schemes available in the WRF-ARW 3.4 model, the Thompson scheme $[27,28]$ has been selected; it is a double-moment scheme, widely used by the hurricane modelling community $[29,30]$ with 6 -class microphysics, with ice and rain number concentrations also predicted and time-split fall terms. In the Thompson scheme, riming growth of snow is required to exceed depositional growth of snow by a factor of 3 before rimed snow transfers into the graupel category, resulting in more realistic values for graupel mixing ratio in the eyewall [1].

For the planetary boundary layer parameterization, the YSU scheme [31] has been adopted, as it is the most chosen
PBL scheme in Monthly Weather Review, the Journal of the Atmospheric Sciences, and the Quarterly Journal of the Royal Meteorological Society articles that presented tropical cyclone simulations using MM5 or WRF in the period of 2006-2010 [32].

Each of the five convection treatments has been explored with two different sets of initial and boundary conditions: the operational global meteorological forecasting model, ECMWF's (European Centre for Medium-Range Weather Forecasts) IFS (Integrated Forecast System, $0.125^{\circ}$ and 3-hour forecast boundary conditions, [33]) and ECMWF's ERA-Interim $\left(0.7^{\circ}\right.$ and 6-hour reanalysis boundary conditions, [34, 35]) reanalysis product.

While IFS and ERA have the same parent modelling system, they are very different in terms of grid spacing and forcing data, thus justifying their adoption for this modelling study. The dynamical core of IFS is hydrostatic, two-timelevel, semi-implicit, and semi-Lagrangian and applies spectral transforms between grid-point space (where the physical parameterizations and advection are calculated) and spectral space. In the vertical direction, the model is discretised using a finite-element scheme. A reduced Gaussian grid is used in the horizontal direction. The IFS version used for Tomas' initial and boundary conditions is Cy36r2 ((https://www .ecmwf.int/en/forecasts/documentation-and-support/evolution-ifs/cycles/cycle-36r2-detail)). The data assimilation system used to produce ERA-Interim is based on a 2006 release of the IFS (Cy31r2 (https://www.ecmwf.int/en/forecasts/documentation-and-support/evolution-ifs/cycles/cycle31r2-summary-changes)). The system includes a 4-dimensional variational analysis (4D-Var) with a 12 -hour analysis window. The spatial resolution of the dataset is approximately $80 \mathrm{~km}$ (T255 spectral) on 60 vertical levels from the surface up to $0.1 \mathrm{hPa}$.

All the simulations encompass the time period from 00UTC on 1 November to 00UTC on 6 November 2010, which includes Tomas' increasingly disorganised phase (from 00UTC on 1 November to 00UTC on 3 November) and the subsequent rapid intensification phase (from 06UTC on 4 November to 06UTC on 5 November). Concerning the choice of the initialization timing, the recommendations of Davis et al. [36] and Xue et al. [37] have been taken into account. Davis et al. [3] found that there was no meaningful difference between storm position errors in the $12 \mathrm{~km}$ and nested higher-resolution forecasts for five landfalling Atlantic hurricanes during 2005. However, TC intensity (in terms of the maximum $10 \mathrm{~m}$ wind) was somewhat better forecasted on the nested grids than on the single $12 \mathrm{~km}$ grid, and the difference was statistically significant at $72 \mathrm{~h}$ and beyond. Xue et al. [37] argued that, for tropical cyclones below hurricane strength, more improvement in the track forecasts comes from high resolution (namely, $4 \mathrm{~km}$ ) at $48 \mathrm{~h}$ and beyond. The high-resolution WRF forecasts produced significantly improved intensity forecasts at $24 \mathrm{~h}$ and beyond in terms of both maximum $10 \mathrm{~m}$ wind speed and minimum sea level pressure. Furthermore, Xue et al. [37] suggested that forecasts of longer ranges than the $48 \mathrm{~h}$ forecasts should also be explored: consequently, the $72 \mathrm{~h}$ and beyond range adopted here is worth to be explored. 
TABLE 2: Set of all ten model configurations explored in this study.

\begin{tabular}{lccc}
\hline Code & $\begin{array}{c}\text { Cumulus } \\
\text { parameterization } \\
\text { parent domain }\end{array}$ & $\begin{array}{c}\text { Cumulus } \\
\text { parameterization } \\
\text { nested domain }\end{array}$ & $\begin{array}{c}\text { Initial and boundary } \\
\text { conditions }\end{array}$ \\
\hline KF-E-IFS & Kain-Fritsch & None & IFS \\
KF-KF-IFS & Kain-Fritsch & Kain-Fritsch & IFS \\
BMJ-BMJ-IFS & Betts-Miller-Janjic & Betts-Miller-Janjic & IFS \\
GD-GD-IFS & Grell-Devenyi & Grell-Devenyi & New Grell \\
NGE-NGE-IFS & New Grell & None & IFS \\
KF-E-ERA & Kain-Fritsch & Kain-Fritsch & ERA-Interim \\
KF-KF-ERA & Kain-Fritsch & Betts-Miller-Janjic & ERA-Interim \\
BMJ-BMJ- ERA & Betts-Miller-Janjic & Grell-Devenyi & ERA-Interim \\
GD-GD- ERA & Grell-Devenyi & New Grell & ERA-Interim \\
NGE-NGE- ERA & New Grell & ERA-Interim \\
\hline
\end{tabular}

Table 2 summarizes the ten different configurations that are adopted for all experiments presented in this study, which focuses on the temporal period corresponding to Tomas' transition over the Greater Antilles area, spanning from 00UTC on 4 November 2010 to 00UTC on 6 November 2010, corresponding to the +72 to +96 hours' time range, when Tomas evolved towards the hurricane conditions.

\section{Results}

A study on Hurricane Tomas' sensitivity has been carried out to determine the most appropriate combination of cumulus parameterizations, IC, and $\mathrm{BC}$ to reproduce the best track, the minimum SLP evolution, the surface wind, and the precipitation associated with the tropical disturbance, with the highest degree of accuracy achievable. As indicated in Table 2, ten combinations of cumulus parameterizations, IC, and $\mathrm{BC}$ have been analysed in order to determine the best model convection treatment for Hurricane Tomas forecast. The results of the $5 \mathrm{~km}$ nested domain have been used for the study, spanning the simulations of 4 and 5 November 2010 which were initialized on 1 November 00UTC, and are compared against NHC's best track data and satellite rainfall measurements.

4.1. Intensity and Trajectory Analysis. Figure 2 displays the tracks of all simulations and NHC's best track from 00UTC on 4 November to 18UTC on5 November 2010 (black line). This figure shows also NHC's track forecast cone (TFC). Its represents the probable track of the centre of the tropical cyclone in a way that two-thirds of the 5-year historical official forecast error fall within the cone: the black cone corresponds to the probability up to 3 days and the red one up to 5 days.

At first sight, it becomes clear that virtually all predicted centre locations of the proto-Tomas, except KF-KF with IFS and ERA experiments, fall within the limits of the 5-day TFC that ends at 00UTC on 6 November (note that the tracks' last time step is $18 \mathrm{UTC}$ on 5 November). In addition, virtually all experiments are relatively closer together and

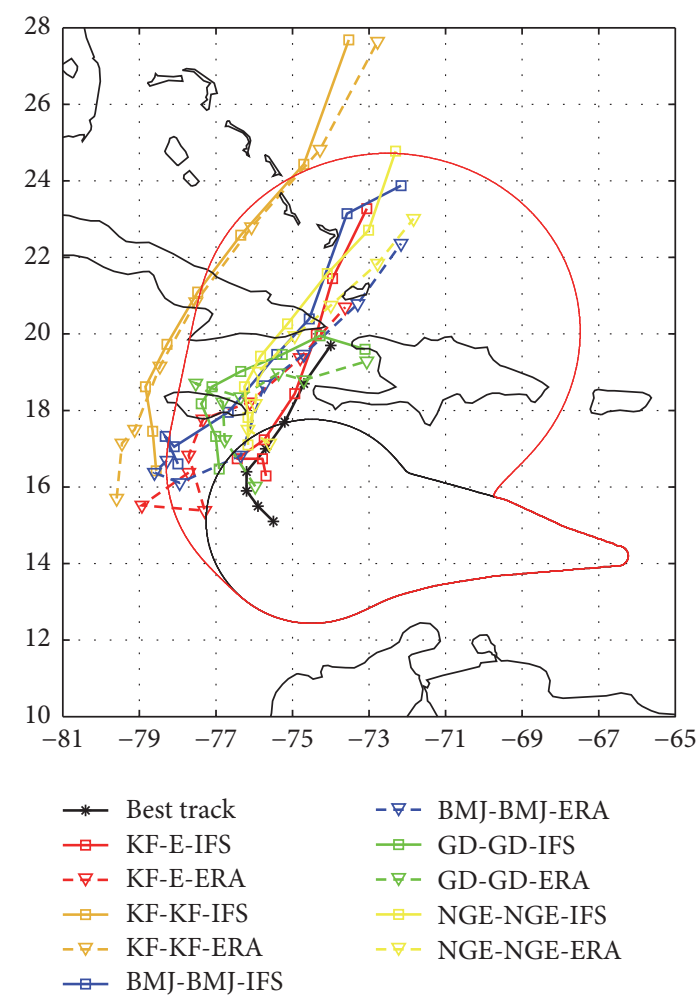

FIgURE 2: Best (black line) and simulated tracks of Hurricane Tomas from 00UTC on 4 November to 18UTC on 5 November 2010 are presented. NHC's track forecast cones for 3 (thin black line) and 5 (thin red line) days are also shown. All the simulations encompass the time period from 00UTC on 1 November to 00UTC on 6 November 2010, which includes the Tomas increasingly disorganised phase (from 00UTC on 1 November to 00UTC on 3 November) and the subsequent rapid intensification phase (from 06UTC on 4 November to 06UTC on 5 November).

either cross through or end their course near the Windward Passage. Differently, KF-KF with IFS and ERA experiments cross through Cuba and are clearly different from the rest. 

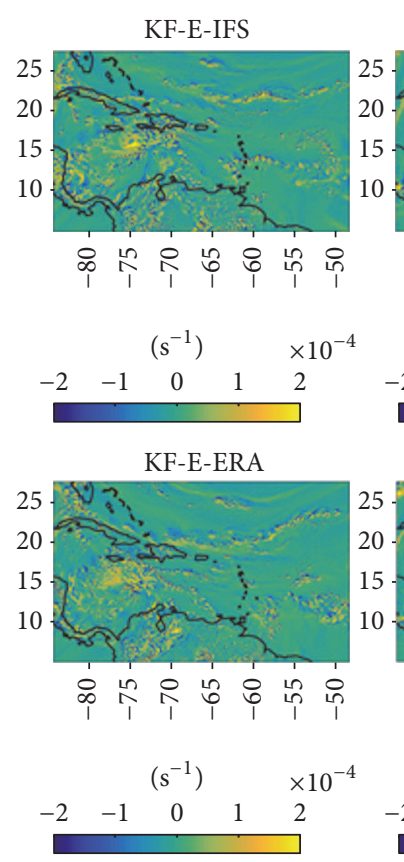

KF-KF-IFS

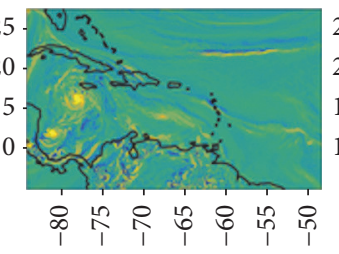

BMJ-BMJ-IFS
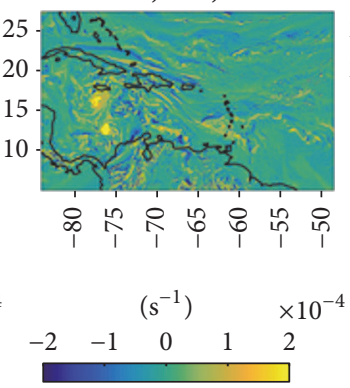

BMJ-BMJ-ERA

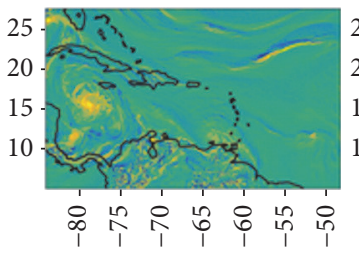

$\left(\mathrm{s}^{-1}\right) \quad \times 10^{-4}$

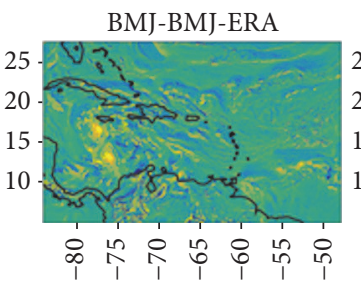

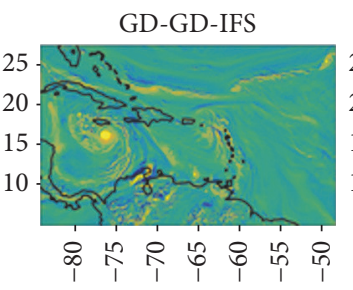
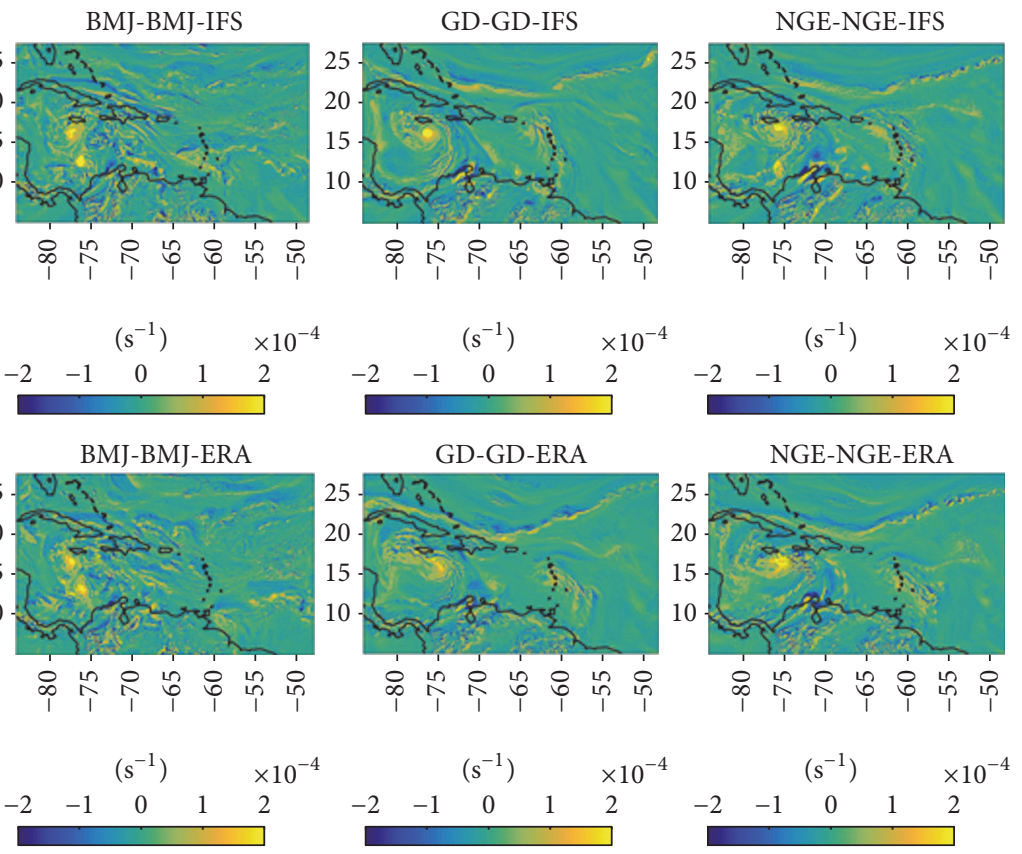

FIGURE 3: Vertical vorticity horizontal cross section at $z=2500 \mathrm{~m}$ for the different WRF experiments at $00 \mathrm{UTC}$ on 4 November 2010.

Another notable characteristic of the tracks in Figure 2 is that, for fixed convective treatment, apart from the KF-E cases, they behave similarly independently by both IC and $\mathrm{BC}$ datasets (IFS and ERA-Interim) used. Contrarily, there is less similarity among simulations with the same IC and BC and different convective schemes. The track variance is much larger for different cumulus schemes than it is for ERA versus IFS.

This points clearly to the stronger degree of control exerted by the choice of convection parameterization over the TC spatiotemporal evolution than by the choice of global model data to feed the model. This statement is further supported by the vorticity field ( $z$-component) at an altitude of $2500 \mathrm{~m}$ predicted by the different experiments at 00UTC on 4 November (Figure 3). Analyzing the results, it is possible to notice that while the large-scale circulation features of the main TC (e.g., elongated convection line around $22.5^{\circ} \mathrm{N}$ and secondary convective region over the Lesser Antilles area) preserve similarities between the different experiments, even 72 hours after the initialization, the choice of the convective parameterization approach influences strongly the proto-Tomas evolution. Both KF-E cases generate finer scale convection activity around the TC intensifying core; conversely, parameterized convection for $5 \mathrm{~km}$ grid spacing domain tends in general to overintensify the predicted TC losing finer scale activity. This is really apparent at 00UTC on 4 November for the KF-KF-IFS, KF-KF-ERA, BMJ-BMJIFS, and BMJ-BMJ-ERA cases when even two neighboring rotating cores emerge. Similar considerations hold also for the water vapor field at $z=2500 \mathrm{~m}$ at 00UTC on 4 November (Figure 4), where all convection parameterized runs produce a moister TC core, especially KF-KF-IFS, KF-KF-ERA, BMJBMJ-IFS, and BMJ-BMJ-ERA cases, characterized also by more intense spiraling bands around the TC core itself as shown by the corresponding vorticity patterns.

In Table 3, the errors of the tracks with respect to the best track are shown: the experiments with the smallest average errors, about $200 \mathrm{~km}$ or below, are those with KF-E and GD-GD for both IFS and ERA datasets. In the case of the two experiments with GD-GD, while being very similar to each other, they are also among the closest to the best track for most instants of the period studied, although they tend to recurve towards the east more than the best track, which shows a more northward movement. In the case of the simulations with KF-E, they much better replicate the observed northeast direction of motion, although, for the run with IFS, that causes proto-Tomas to translate farther north than the best track indicates. On the opposite extreme, and as already mentioned before, we find the two experiments with KF-KF performing the worst of the whole study, with average track errors of more than $500 \mathrm{~km}$ and travelling outside the TFC for most of their timespan.

It is worth mentioning that the NHC official skill (OFCL, mean errors for the 5-year period of 2005-2009) baseline track forecast errors are about $180 \mathrm{~km}$ for 48 hours' forecast, $270 \mathrm{~km}$ for 72 hours' forecast, $360 \mathrm{~km}$ for 96 hours' forecast, and $470 \mathrm{~km}$ for 120 hours' forecast: this confirms once more the very good performances of experiments KF-E and GDGD at +96 hours (00UTC on 5 November) and +114 hours (18UTC on 5 November), both below the OFCL target values, also slightly better than OFCL (Tomas) values for NHC operational models [9].

Having identified the experiment subsets of KF-E and GD-GD, both with IFS and ERA datasets, as best-performing from the point of view of the system's spatial motion, now 


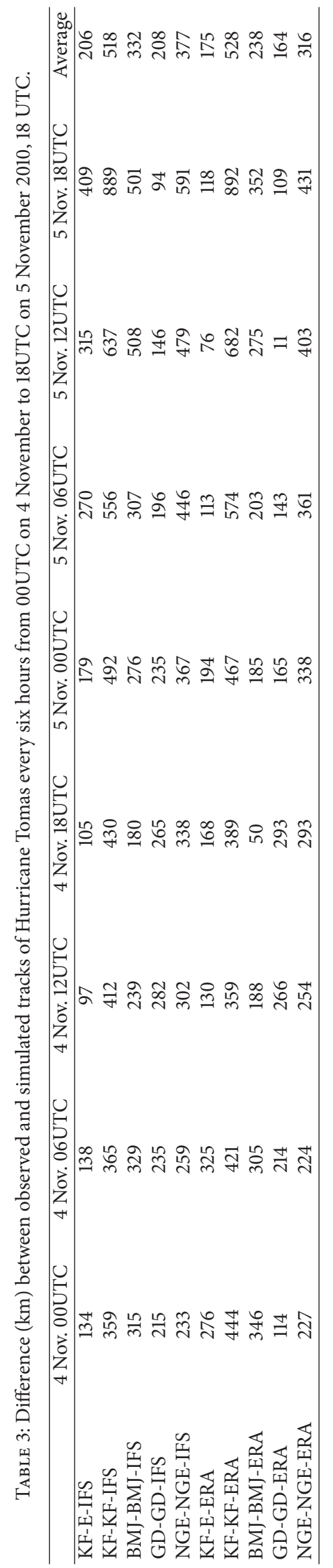



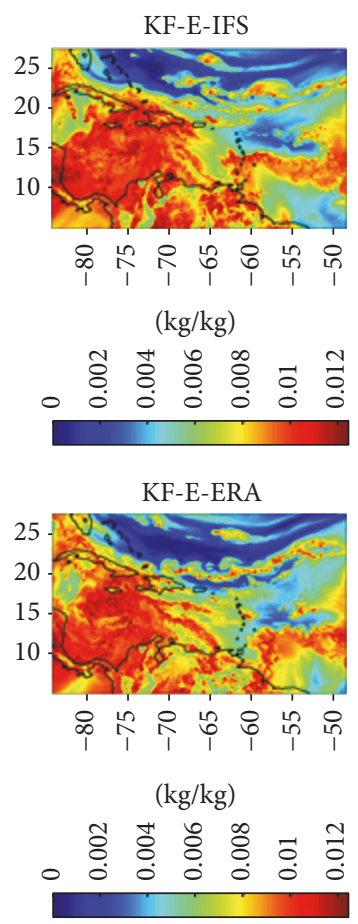
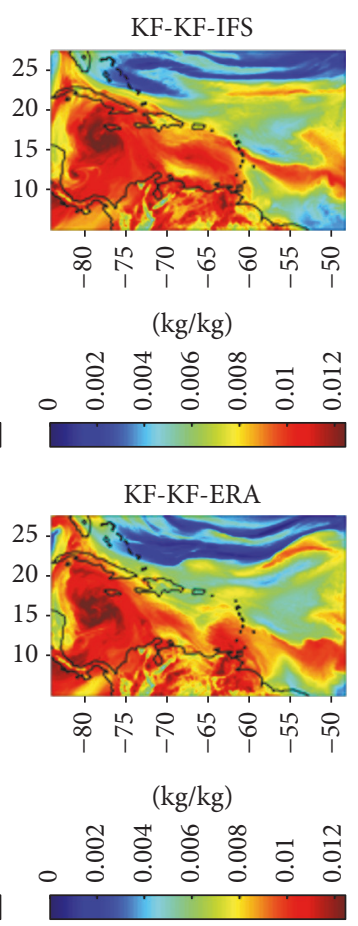

BMJ-BMJ-IFS

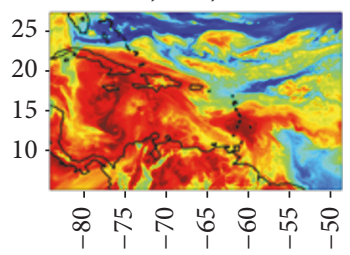

$(\mathrm{kg} / \mathrm{kg})$

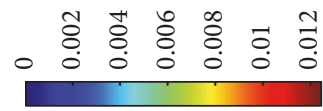

BMJ-BMJ-ERA

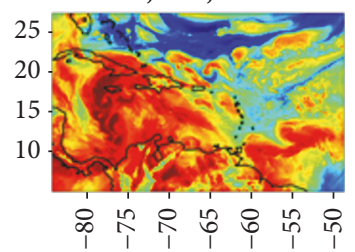

$(\mathrm{kg} / \mathrm{kg})$
GD-GD-IFS

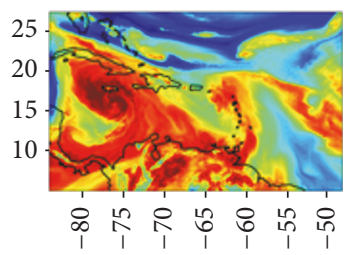

$(\mathrm{kg} / \mathrm{kg})$

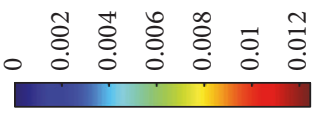

GD-GD-ERA

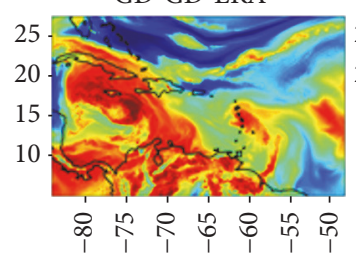

$(\mathrm{kg} / \mathrm{kg})$
NGE-NGE-IFS

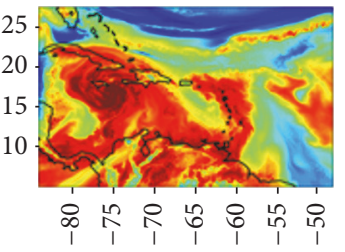

$(\mathrm{kg} / \mathrm{kg})$

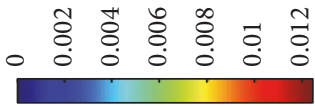

NGE-NGE-ERA

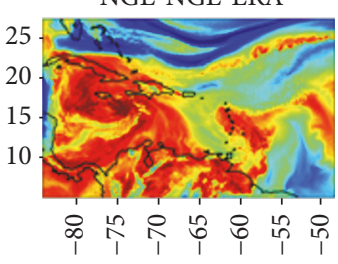

$(\mathrm{kg} / \mathrm{kg})$

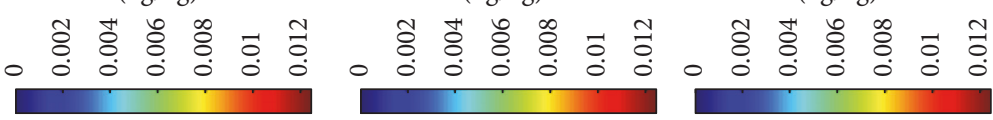

FIGURE 4: Water vapor horizontal cross section at $z=2500 \mathrm{~m}$ for the different WRF experiments at 00UTC on 4 November 2010.

we turn to the analysis of the minimum SLP and maximum sustained surface wind.

The intensity of Tomas was poorly handled in the NHC forecasts. The official forecast intensity errors were greater than the mean official errors for the previous 5-year period at all forecast intervals and considerably greater at 48 through $120 \mathrm{~h}$ [9].

Figure 5 shows their respective evolutions in comparison to the best track for each simulation (black for SLP and red for wind; solid for best track and dashed for prediction) and also presents their average mean absolute errors (MAEs). From a quick visual inspection of Figure 5, it is apparent that the best performers in terms of both minimum SLP and maximum surface wind evolutions simultaneously are the KF-E with IFS and with ERA. Additionally, both KF-E-IFS and KF-E-ERA reproduce accurately the rapid intensification phase of Hurricane Tomas with an increase in the maximum sustained winds of $30 \mathrm{kt}$ in the period from 0600UTC on 4 November $(40 \mathrm{kt})$ to $0600 \mathrm{UTC}$ on 5 November $(70 \mathrm{kt})$. They have the two lowest pressure MAEs (1.58 and $4.03 \mathrm{hPa}$, resp.) and also lowest wind MAEs (4.19 and $3.03 \mathrm{~m} / \mathrm{s}$ ), which is only bettered by the BMJ-BMJ-IFS simulation $(2.80 \mathrm{~m} / \mathrm{s})$. In fact, BMJ-BMJ-ERA has an acceptable wind MAE of $5.12 \mathrm{~m} / \mathrm{s}$, making that experiment the fourth best from this viewpoint; however, both BMJ-BMJ simulations definitely overestimate the pressure fall with respect to the best track and the KF-E experiment group, resulting into exaggerated rapid intensification of the predicted Tomas experiment. Interesting enough, all these 4 experiments have intensity error lower than NHC official skill baseline errors, which is about $9.5 \mathrm{~m} / \mathrm{s}$ for 96 hours' forecast.
For the GD-GD experiments, which were among the best for track error, for the IFS run, the pressure and wind errors indicate greater error on 4 November than other experiments shown in Figure 5, while the ERA run significantly underestimates intensity, particularly on 5 November: GD-GD experiments are not able to capture properly the rapid intensification of Hurricane Tomas. Finally, turning to the results for the KF-KF and NGE-NGE groups, they are clearly the two parameterization experiment sets that overintensify the most both pressure and wind persistently during the whole timespan: this is due to the fact that KF and NGE parameterizations promote too strong convection (see Figures 4-6 and 7-9), which results in a greater intensity and makes the storm more resilient to shear and steering from environmental forcing.

Another aspect to note from the overall analysis is the relationship between the translational speed of the protohurricanes and their degree of intensification, an idea pointed out by Mei et al. [38]. Although our simulations do not use the 1D model option for ocean mixed-layer representation and hence do not incorporate wind-induced SST cooling with its negative feedback to the storm, yet, intriguingly enough, our results show that the simulations creating the most intense proto-Tomas perturbations, the groups KF-KF and NGENGE, are also those that bring the system furthest from their origin and so create the fastest translational speeds.

\subsection{Precipitation}

4.2.1. Analysis Methodology. Since this study focuses on the western portion of the Caribbean, where rain gauges and 


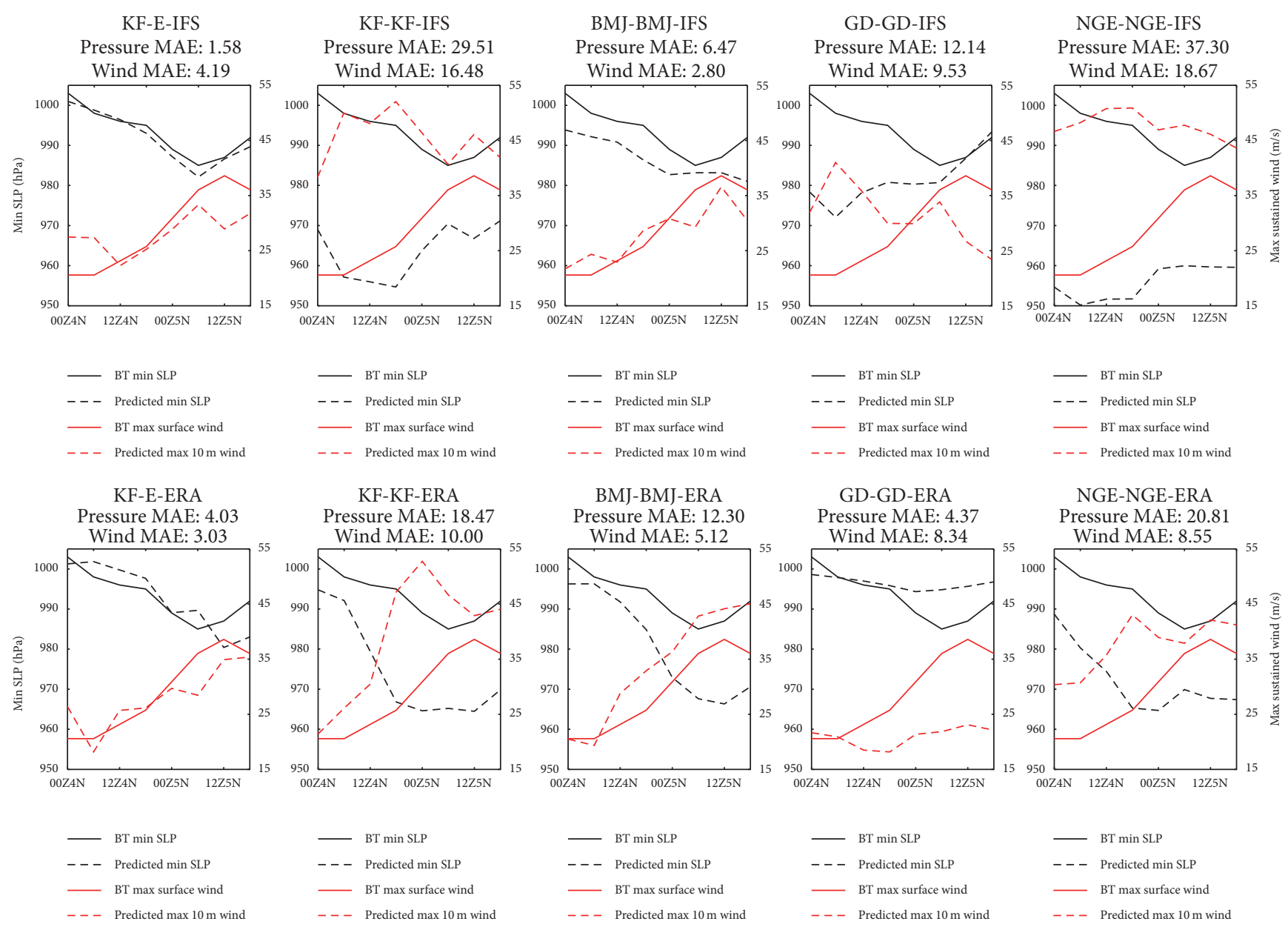

FIGURE 5: Evolutions of observed (solid) and predicted (dashed) minimum SLP (in black) and maximum sustained surface wind (in red) of Hurricane Tomas from 00UTC on 4 November to 18UTC on 5 November 2010, with respective average MAEs on top of each panel.

radar data are hardly available, rainfall amounts for Hurricane Tomas are estimated from satellite measurements, and in particular three datasets are considered: TRMM 3B42 (spatial resolution: $0.25 \times 0.25$ degrees; temporal resolution: 3 hours; [39]), GSMaP (spatial resolution: $0.1 \times 0.1$ degrees; temporal resolution 1: hour; [40]), and PERSIANN-CDR (spatial resolution: $0.25 \times 0.25$ degrees; temporal resolution: 3 hours; [41]). Among these, PERSIANN-CDR is the newest dataset, while TRMM 3B42 can probably be considered as the most reliable $[42,43]$. The fields shown in Figure 6, for the simulations, spatial grid spacing of $5 \mathrm{~km}$, and for GSMaP dataset, about $10 \mathrm{~km}$, have been aggregated, for ease of comparison purposes, to the same resolution as TRMM $3 \mathrm{~B} 42$ and PERSIANN-CDR datasets, $25 \mathrm{~km}$.

To support the visual analysis of the 48-hour rainfall fields, a more quantitative (although without the temporal dimension) analysis of the phenomenon has been performed: then the Method for Object-Based Diagnostic Evaluation (MODE, [44-47], developed at Research Application Laboratory NCAR/Boulder (USA) and intended to reproduce a human analysts' evaluation of the forecast performance, has been adopted.

The MODE analysis is performed using a multistep automated process. A convolution filter radius $r$ and a threshold $t$ are applied to the raw field to identify the objects. When the objects are identified, some attributes regarding geometrical features of the objects (such as location, size, aspect ratio, and complexity) and precipitation intensity (percentiles, etc.) are computed. These attributes are used to merge objects within the same forecast/observation field, to match forecast and observed objects, and to summarize the performance of the forecast by attributes comparison. Finally, the interest value combines in a Total Interest function all the attributes computed in the object analysis, providing an indicator of the overall performance of matching and merging between observed and simulated objects. In our experiment, we have empirically chosen the convolution disk radius and convolution threshold, so that this choice would recognise precipitation patterns similar to those a forecaster would identify. After a set of experiments, we fixed the value of the convolution radius to one grid point and the threshold of the convoluted field to $100 \mathrm{~mm} / 48$ hours.

4.2.2. Analysis Results. The purpose here is to establish which cumulus parameterization and global model combination best represents total rainfall on 4 and 5 November.

Figure 6 shows total rainfall for the two days for all simulations and observation datasets. Looking at the results 

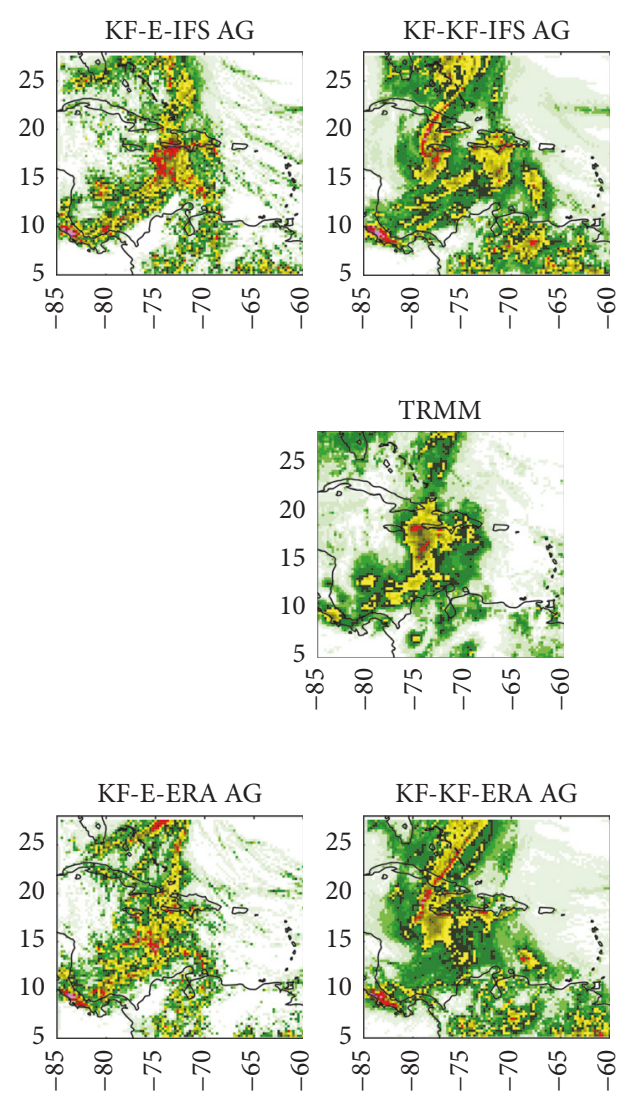
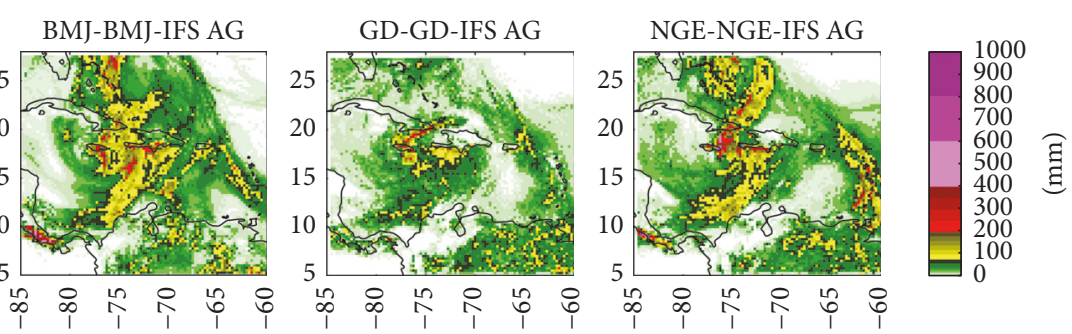

(a)
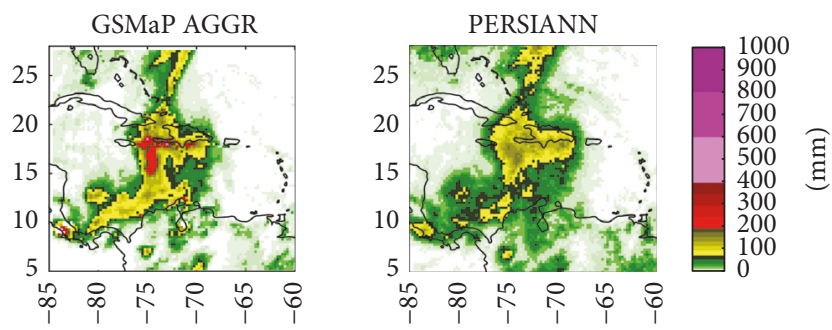

(b)
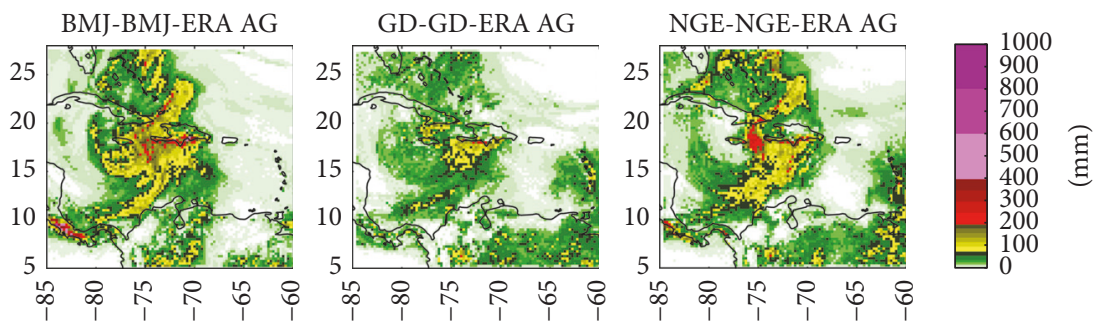

(c)

FIGURE 6: Rainfall depth from 00UTC on 4 November to 00UTC on 6 November 2010. Satellite observations (TRMM 3B42, GSMaP, and PERSIANN) in (b) simulations using KF-E, KF-KF, BMJ-BMJ, GD-GD, and NGE-NGE, respectively, in (a) those fed with IFS and in (c) those with ERA-Interim.

of all three satellite datasets, it is evident that there is a substantial degree of differences among them. However, there are some important commonalities between them as well. For example, the rainfall maximum in all three satellite datasets is consistently located over the Caribbean Sea between Hispaniola and Jamaica. The region of high precipitation values extends to the south and west, reaching the coasts of Venezuela and Colombia. Also an area of consistent precipitation extends from the Windward Passage to the north in each of the observation fields. In any case, they always coincide to place over the westernmost tips of La Hispaniola the highest rainfall amounts caused by Hurricane Tomas. Now, analyzing our simulations, one of the most important results is that the two experiments with explicit treatment of convection in the inner domain (KF-E-IFS and KF-E-ERA) create well organised patterns. Therefore, rainfall spatial distribution is in good agreement with observations. In addition, KF-E-IFS and KF-E-ERA simulations do not create extensive areas of artificial precipitation in the rest of the domain as do most of the rest of simulations, which all use convective parameterizations in the inner domain. This suggests that getting the convective organisation correct is important for not only intensity but also track, in agreement with results of $\mathrm{Li}$ and $\mathrm{Pu}$ [13]. Another feature that further favours the no-parameterization simulations with respect to the others is the location of the maximum amounts, especially in the case of KF-E-IFS, and to a lesser degree KF-E-ERA. In this point, also BMJ-BMJ-ERA performs remarkably well, but the same cannot be said of its counterpart BMJ-BMJ-IFS. On the other hand, it is noted that explicit convection runs do not produce enough light-to-moderate rain (yellows).

As described in the previous chapter, the MODE analysis has been applied to support and strengthen the visual analysis of the rainfall fields. The results are summarized in Table 4: BMJ-BMJ and NGE-NGE-ERA outperform all other microphysics schemes in terms of total interest performances, with very good performances also for BMJ-BMJ-ERA, KEE-IFS, and KF-E-ERA runs, especially when the TRMM dataset, the most reliable one $[42,43]$, is considered. Negative performances are, instead, shown by GD-GD-IFS, KF-KFERA, and GD-GD-ERA.

As final analysis, Figure 7 shows the cumulative distribution function of the rainfall for 4 and 5 November, including both the numerical experiments and observation datasets. It is apparent also in this figure that the three satellite measurements disagree considerably among each other, as already discussed. In any case, the two explicit convection simulations that performed the best in the intensity (wind 
TABLE 4: Total interest results with respect to each of the three different precipitation observational datasets.

\begin{tabular}{lcccc}
\hline & TRMM & PERSIANN & GSMaP & 0.989 \\
KF-E-IFS & 0.944 & 0.949 & 0.924 & 0.961 \\
KF-KF-IFS & 0.938 & 0.938 & 0.996 & 0.933 \\
BMJ-BMJ-IFS & 0.966 & 0.967 & 0.853 & 0.976 \\
GD-GD-IFS & 0.888 & 0.907 & 0.968 & 0.883 \\
NGE-NGE-IFS & 0.947 & 0.935 & 0.949 & 0.950 \\
KF-E-ERA & 0.975 & 0.916 & 0.817 & 0.947 \\
KF-KF-ERA & 0.857 & 0.885 & 0.996 & 0.853 \\
BMJ-BMJ-ERA & 0.943 & 0.949 & 0.834 & 0.963 \\
GD-GD-ERA & 0.850 & 0.898 & 0.986 & 0.861 \\
NGE-NGE-ERA & 0.955 & 0.975 & & 0.972 \\
\hline
\end{tabular}

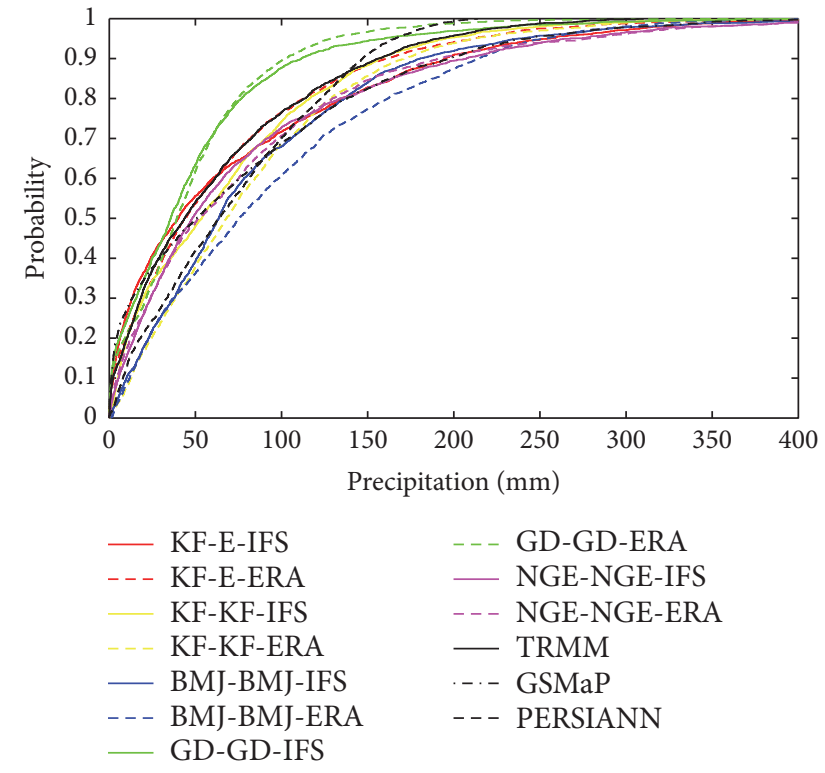

FIGURE 7: Cumulative distribution function for rainfall from 00UTC on 4 November to 00UTC on 6 November 2010 for each simulation and observation dataset; only the values within 5 degrees of the approximate storm path centre are considered.

and pressure) analysis and were among the top ones also from the trajectory, shown here in solid (KF-E-IFS) and dashed (KF-E-ERA) red lines, continue to be among the closest to the observational datasets available. Looking at KF-E-IFS probability line, it is rather close for most rainfall values (except for the highest extreme, not shown here) to the GSMaP curve, especially at the beginning and then from about 0.8 onwards. For KF-E-ERA, its curve is particularly similar to the TRMM 3B42 dataset, and it closely follows it from 0 and up to 0.85 , where KF-E-ERA and TRMM 3B42 dataset curves start to diverge somewhat and TRMM 3B42 remains on the lower side. Finally, it is evident that GDGD-IFS and GD-GD-ERA have too much light precipitation, while the opposite is true for BMJ-BMJ-ERA.

\section{Conclusions}

Two of the well-known error sources that influence the numerical simulation of severe hydrometeorological phenomena are analysed in this study, that is, the uncertainty associated with initial and boundary conditions and the influence of a parameterization scheme on the subgrid physical processes representation. Ten simulations have been performed combining five ways to represent convective processes and making use of two different global models to feed our regional numerical weather prediction model. For the specific case of Hurricane Tomas and for days 4 and 5 November 2010, when a rapid intensification phase was also observed, the results of this study clearly point to the advantage of not using a convective parameterization at a scale of $5 \mathrm{~km}$ while keeping it at the parent domain $(15 \mathrm{~km})$. By doing so, critical TC indicators such as maximum surface wind, minimum SLP, trajectory, and rainfall depths are simulated successfully and reasonably approach the values of NHC's best track and satellite measurements. It is also shown here that the choice of convective parameterization has a higher impact on the intensity and trajectory of the $\mathrm{TC}$, as well as on the overall rainfall pattern, than the choice of global model data used to feed the model. Combining all the results of the analysis in terms of best performance, the configuration with higher positive responses for the Tomas postprocessing evaluation seems to be the one with explicit treatment convection on the smaller domain. On the other hand, it is also evident from this case study that grid resolution of the order of $5 \mathrm{~km}$ has to be considered as the higher limit for simulations on which no convective parameterization could be adopted. Since a possible limitation of the present study is due to the fact that the conclusions are based on a single model study for one individual case, a confirmation using additional models and performing more case studies is under evaluation. Then, some preliminary simulations about the recent Matthew Hurricane (October 2016) are hereafter presented, focusing on the best and worst performing settings for Thomas (KF-E-IFS and KF-KF-IFS configurations). The results are reported hereafter in terms of best track and minimum pressure, with the regard to the Matthew simulation initialized at 00UTC on 1 October 2016, 


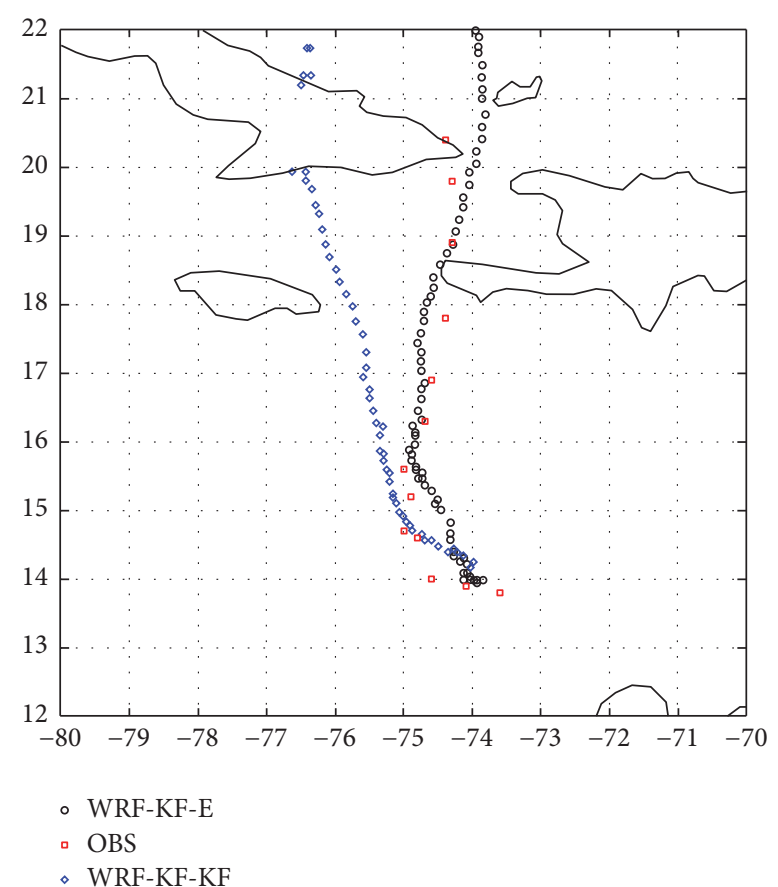

FIGURE 8: Comparison between the observed Matthew Hurricane best track (2 October-5 October 2016, 6-hourly step) and the predicted ones by KF-E-IFS and KF-KF-IFS WRF simulations (at $5 \mathrm{~km}$, hourly step).

when Matthew Hurricane was already a category 2 hurricane: in agreement with Xue et al.s [37] conclusions, the track and intensity plots are presented for the time period of +24 hours onwards. Figure 8 shows that the KF-E-IFS track is very close to the observed one, making landfall on Haiti around 06UTC on 4 October 2016, as in the observed event. Conversely, the KF-KF-IFS experiment diverges significantly, making landfall on Cuba around 00UTC on 4 October 2016. The KF-KF-IFS experiment's behaviour for the case of Matthew Hurricane is indeed very consistent with the one that occurred for the case of Tomas Hurricane, when the trajectory diverged significantly towards Cuba once more. KF-E-IFS experiment performs better than KF-KF-IFS one also for the minimum pressure (Figure 9) and maximum sustained 1-minute wind speed (not shown) with regard to the case of Matthew Hurricane. Concerning the minimum pressure, KF-KF-IFS experiment converges more quickly towards the observed values (in 72 hours) than KF-E-IFS (in 96 hours), but because of the wrong trajectory and related landfall on Cuba, the minimum pressure suddenly increases, when the observed one reaches its minimum values at 00-12UTC on 4 October 2016, as correctly captured by KF-E-IFS simulation. Thus, even if these are preliminary results, they seem to validate the Tomas settings chosen as the best ones.

\section{Conflicts of Interest}

The authors declare that there are no conflicts of interest regarding the publication of this paper.

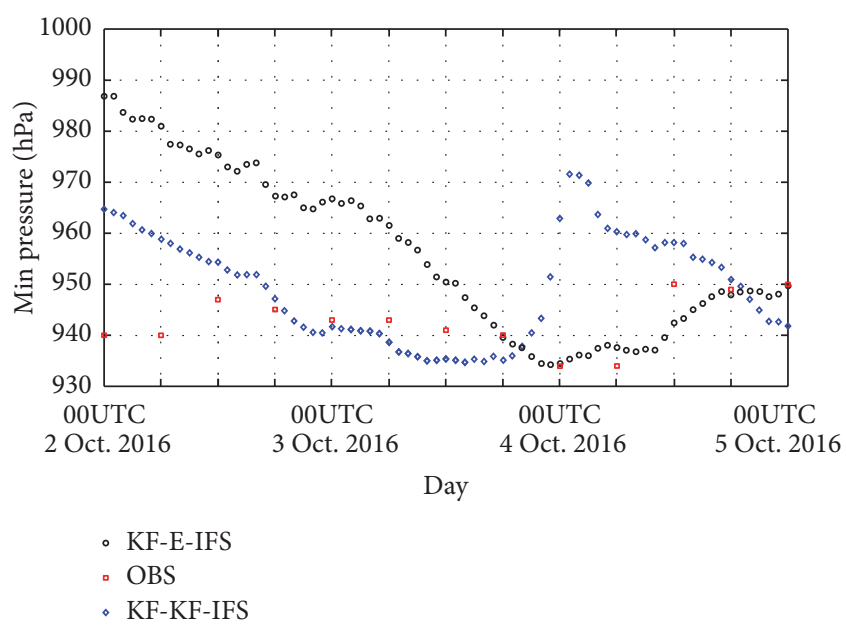

FIgURE 9: Comparison between the observed Matthew minimum pressure (2 October-5 October 2016, 6-hourly step) and the predicted ones by KF-E-IFS and KF-KF-IFS WRF simulations (at $5 \mathrm{~km}$, hourly step).

\section{Acknowledgments}

Antonio Parodi would like to acknowledge the support of Project FP7 DRIHM (Distributed Research Infrastructure for Hydro-Meteorology, 2011-2015) (Contract no. 283568). Thanks are due to the LRZ Supercomputing Centre, Garching, Germany, where the numerical simulations were performed on the SuperMUC Petascale System (Project ID: pr45de).

\section{References}

[1] A. O. Fierro, R. F. Rogers, F. D. Marks, and D. S. Nolan, “The Impact of horizontal grid spacing on the microphysical and kinematic structures of strong tropical cyclones simulated with the WRF-ARW model," Monthly Weather Review, vol. 137, no. 11, pp. 3717-3743, 2009.

[2] X. Zhang, K.-S. Yeh, T. S. Quirino et al., "HWRFx: improving hurricane forecasts with high-resolution modeling," Computing in Science and Engineering, vol. 13, no. 1, Article ID 5601668, pp. 13-21, 2011.

[3] C. Davis, W. Wang, J. Dudhia, and R. Torn, "Does increased horizontal resolution improve hurricane wind forecasts?" Weather and Forecasting, vol. 25, no. 6, pp. 1826-1841, 2010.

[4] R. Chandrasekar and C. Balaji, "Sensitivity of tropical cyclone Jal simulations to physics parameterizations," Journal of Earth System Science, vol. 121, no. 4, pp. 923-946, 2012.

[5] M. K. Biswas, L. Bernardet, and J. Dudhia, "Sensitivity of hurricane forecasts to cumulus parameterizations in the HWRF model," Geophysical Research Letters, vol. 41, no. 24, pp. 91139119, 2014.

[6] D.-L. Zhang, L. Zhu, X. Zhang, and V. Tallapragada, "Sensitivity of idealized hurricane intensity and structures under varying background flows and initial vortex intensities to different vertical resolutions in HWRF," Monthly Weather Review, vol. 143, no. 3, pp. 914-932, 2015.

[7] R. D. Torn, "Performance of a mesoscale ensemble Kalman Filter (EnKF) during the NOAA high-resolution hurricane test," Monthly Weather Review, vol. 138, no. 12, pp. 4375-4392, 2010. 
[8] S.-Y. Hong, J. Dudhia, and S.-H. Chen, "A revised approach to ice microphysical processes for the bulk parameterization of clouds and precipitation," Monthly Weather Review, vol. 132, no. 1, pp. 103-120, 2004.

[9] R. J. Pasch and T. B. Kimberlain, "Tropical Cyclone Report Hurricane Tomas (AL212010)," 2011, http://www.NHC.noaa.gov/ pdf/TCR-AL212010_Tomas.pdf.

[10] M. A. Bender and I. Ginis, "Real-case simulations of hurricaneocean interaction using a high-resolution coupled model: effects on hurricane intensity," Monthly Weather Review, vol. 128, no. 4, pp. 917-946, 2000.

[11] S. B. Goldenberg, S. G. Gopalakrishnan, V. Tallapragada et al., "The 2012 triply nested, high-resolution operational version of the hurricane weather research and forecasting model (HWRF): track and intensity forecast verifications," Weather and Forecasting, vol. 30, no. 3, pp. 710-729, 2015.

[12] R. Rogers, S. Aberson, M. Black et al., "The intensity forecasting experiment: A NOAA multiyear field program for improving tropical cyclone intensity forecasts," Bulletin of the American Meteorological Society, vol. 87, no. 11, pp. 1523-1537, 2006.

[13] X. Li and Z. Pu, "Sensitivity of numerical simulations of the early rapid intensification of Hurricane emily to cumulus parameterization schemes in different model horizontal resolutions," Journal of the Meteorological Society of Japan, vol. 87, no. 3, pp. 403-421, 2009.

[14] Y. Sun, L. Yi, Z. Zhong, Y. Hu, and Y. Ha, "Dependence of model convergence on horizontal resolution and convective parameterization in simulations of a tropical cyclone at grayzone resolutions," Journal of Geophysical Research Atmospheres, vol. 118, no. 14, pp. 7715-7732, 2013.

[15] X. Sun and A. P. Barros, "High resolution simulation of tropical storm Ivan (2004) in the Southern appalachians: role of planetary boundary-layer schemes and cumulus parametrization," Quarterly Journal of the Royal Meteorological Society, vol. 140, no. 683, pp. 1847-1865, 2014.

[16] M. S. Gentry and G. M. Lackmann, The Sensitivity of WRF Simulations of Hurricane Ivan to Choice of Cumulus Parameterization, North Carolina State University, 2006.

[17] S. A. Braun, R. Kakar, E. Zipser et al., "NASA's genesis and rapid intensification processes (GRIP) field experiment," Bulletin of the American Meteorological Society, vol. 94, no. 3, pp. 345-363, 2013.

[18] E. Shamir, K. P. Georgakakos, C. Spencer, T. M. Modrick, M. J. Murphy Jr., and R. Jubach, "Evaluation of real-time flash flood forecasts for Haiti during the passage of hurricane tomas," Natural Hazards, vol. 67, no. 2, pp. 459-482, 2013.

[19] W. C. Skamarock, J. B. Klemp, J. Dudhia et al., 2005, A description of the Advanced Research WRF version 2. NCAR Tech. Note NCAR/TN-468+STR.

[20] S. G. Gopalakrishnan, S. Goldenberg, T. Quirino et al., “Toward improving high-resolution numerical hurricane forecasting: influence of model horizontal grid resolution, initialization, and physics," Weather and Forecasting, vol. 27, no. 3, pp. 647-666, 2012.

[21] J. S. Kain, "The kain-fritsch convective parameterization: an update," Journal of Applied Meteorology, vol. 43, no. 1, pp. 170181, 2004.

[22] R. Rogers, "Convective-scale structure and evolution during a high-resolution simulation of tropical cyclone rapid intensification," Journal of the Atmospheric Sciences, vol. 67, no. 1, pp. 44-70, 2010.
[23] A. K. Betts, "A new convective adjustment scheme. part I: observational and theoretical basis," Quarterly Journal of the Royal Meteorological Society, vol. 112, no. 473, pp. 677-691, 1986.

[24] A. K. Betts and M. J. Miller, "A new convective adjustment scheme. part II: single column tests using GATE wave, BOMEX, ATEX and arctic air-mass data sets," Quarterly Journal of Royal Meteorological Society, vol. 112, no. 473, pp. 693-709, 1986.

[25] G. A. Grell and D. Dévényi, "A generalized approach to parameterizing convection combining ensemble and data assimilation techniques," Geophysical Research Letters, vol. 29, no. 14, pp. 381-38-4, 2002.

[26] W. Skamarock, J. B. C, J. Dudhia et al., "A description of the advanced research WRF version 3. NCAR technical note, NCAR/TN\u2013475?STR," 2008, http://www.mmm.ucar.edu/ wrf/users/docs/arw_v3.pdf.

[27] G. Thompson, R. M. Rasmussen, and K. Manning, "Explicit forecasts of winter precipitation using an improved bulk microphysics scheme, part I: description and sensitivity analysis," Monthly Weather Review, vol. 132, no. 2, pp. 519-542, 2004.

[28] G. Thompson, P. R. Field, R. M. Rasmussen, and W. D. Hall, "Explicit forecasts of winter precipitation using an improved bulk microphysics scheme. part II. implementation of a new snow parameterization," Monthly Weather Review, vol. 136, no. 12, pp. 5095-5115, 2008.

[29] W. K. Tao, J. J. Shi, S. S. Chen et al., “The impact of microphysical schemes on hurricane intensity and track," Asia-Pacific Journal of Atmospheric Sciences, vol. 47, no. 1, pp. 1-16, 2011.

[30] R. G. Fovell, Y. P. Bu, K. L. Corbosiero et al., Influence of Cloud Microphysics And Radiation on Tropical Cyclone Structure and Motion, vol. 56, Meteorological Monographs, 2016.

[31] S. Hong, Y. Noh, and J. Dudhia, "A new vertical diffusion package with an explicit treatment of entrainment processes," Monthly Weather Review, vol. 134, no. 9, pp. 2318-2341, 2006.

[32] J. D. Kepert, "Choosing a boundary layer parameterization for tropical cyclone modeling," Monthly Weather Review, vol. 140, no. 5, pp. 1427-1445, 2012.

[33] A. J. Simmons, D. M. Burridge, M. Jarraud, C. Girard, and W. Wergen, "The ECMWF medium-range prediction models development of the numerical formulations and the impact of increased resolution," Meteorology and Atmospheric Physics, vol. 40, no. 1-3, pp. 28-60, 1989.

[34] D. P. Dee, S. M. Uppala, A. J. Simmons et al., "The ERAInterim reanalysis: configuration and performance of the data assimilation system," Journal of the Royal Meteorological Society, vol. 137, no. 656, pp. 553-597, 2011.

[35] A. Simmons, C. Uppala, D. Dee, and S. Kobayashi, "ERAInterim: New ECMWF reanalysis products from," ECMWF Newsl, vol. 110, pp. 25-35, 2007.

[36] C. A. Davis, W. Wang, S. S. Chen et al., "Prediction of landfalling hurricanes with the advanced hurricane WRF model," Monthly Weather Review, vol. 136, no. 6, pp. 1990-2005, 2008.

[37] M. Xue, J. Schleif, F. Kong, K. W. Thomas, Y. Wang, and K. $\mathrm{Zhu}$, "Track and intensity forecasting of hurricanes: impact of convection-permitting resolution and global ensemble Kalman filter analysis on 2010 Atlantic season forecasts," Weather and Forecasting, vol. 28, no. 6, pp. 1366-1384, 2013.

[38] W. Mei, C. Pasquero, and F. Primeau, "The effect of translation speed upon the intensity of tropical cyclones over the tropical ocean," Geophysical Research Letters, vol. 39, no. 7, Article ID L07801, 2012. 
[39] T. Iguchi, T. Kozu, R. Meneghini, J. Awaka, and K. I. Okamoto, "Rain-profiling algorithm for the TRMM precipitation radar," Journal of Applied Meteorology, vol. 39, no. 12, pp. 2038-2052, 2000.

[40] T. Kubota, S. Shige, H. Hashizume et al., "Global precipitation map using satellite-borne microwave radiometers by the GSMaP project: production and validation," IEEE Transactions on Geoscience and Remote Sensing, vol. 45, no. 7, pp. 2259-2275, 2007.

[41] H. Ashouri, K.-L. Hsu, S. Sorooshian et al., "PERSIANN-CDR: daily precipitation climate data record from multisatellite observations for hydrological and climate studies," Bulletin of the American Meteorological Society, vol. 96, no. 1, pp. 69-83, 2015.

[42] Z. Chen, Y. Qin, Y. Shen, and S. Zhang, "Evaluation of global satellite mapping of precipitation project daily precipitation estimates over the Chinese mainland," Advances in Meteorology, vol. 2016, Article ID 9365294, 15 pages, 2016.

[43] J. Liu, Z. Duan, J. Jiang, and A. Zhu, "Evaluation of three satellite precipitation products TRMM 3B42, CMORPH, and PERSIANN over a subtropical watershed in China," Advances in Meteorology, vol. 2015, Article ID 151239, 13 pages, 2015.

[44] B. G. Brown, J. H. Gotway, R. Bullock et al., "The model evaluation tools (MET): community tools for forecast evaluation," in Proceedings of the 25th Conference on International Interactive Information and Processing Systems (IIPS) for Meteorology, Oceanography, and Hydrology, vol. January 9, p. 6, Phoenix, AZ, USA, 2009, Meteor. Soc.

[45] C. A. Davis, B. Brown, and R. Bullock, "Object-based verification of precipitation forecasts. part I: methodology and application to mesoscale rain areas," Monthly Weather Review, vol. 134, no. 7, pp. 1772-1784, 2006.

[46] C. Davis, B. Brown, and R. Bullock, "Object-based verification of precipitation forecasts. part II: application to convective rain systems," Monthly Weather Review, vol.134, pp. 1785-1795, 2006.

[47] C. A. Davis, B. G. Brown, R. Bullock, and J. Halley-Gotway, "The method for object-based diagnostic evaluation (MODE) applied to numerical forecasts from the 2005 NSSL/SPC Spring Program," Weather and Forecasting, vol. 24, no. 5, pp. 1252-1267, 2009. 

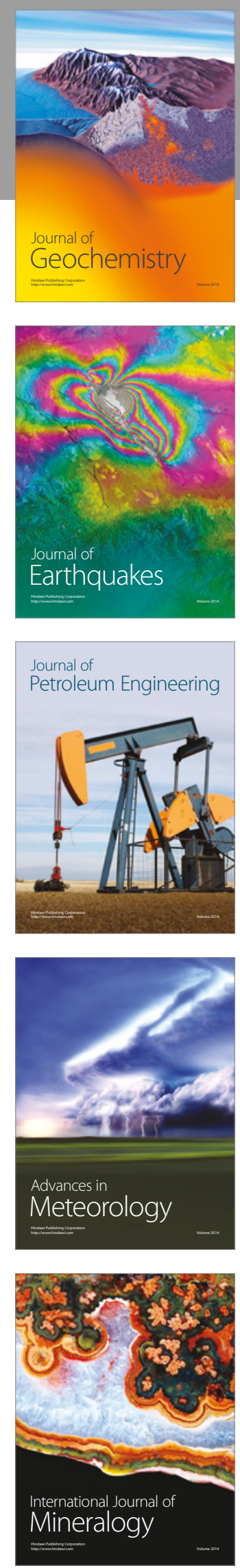
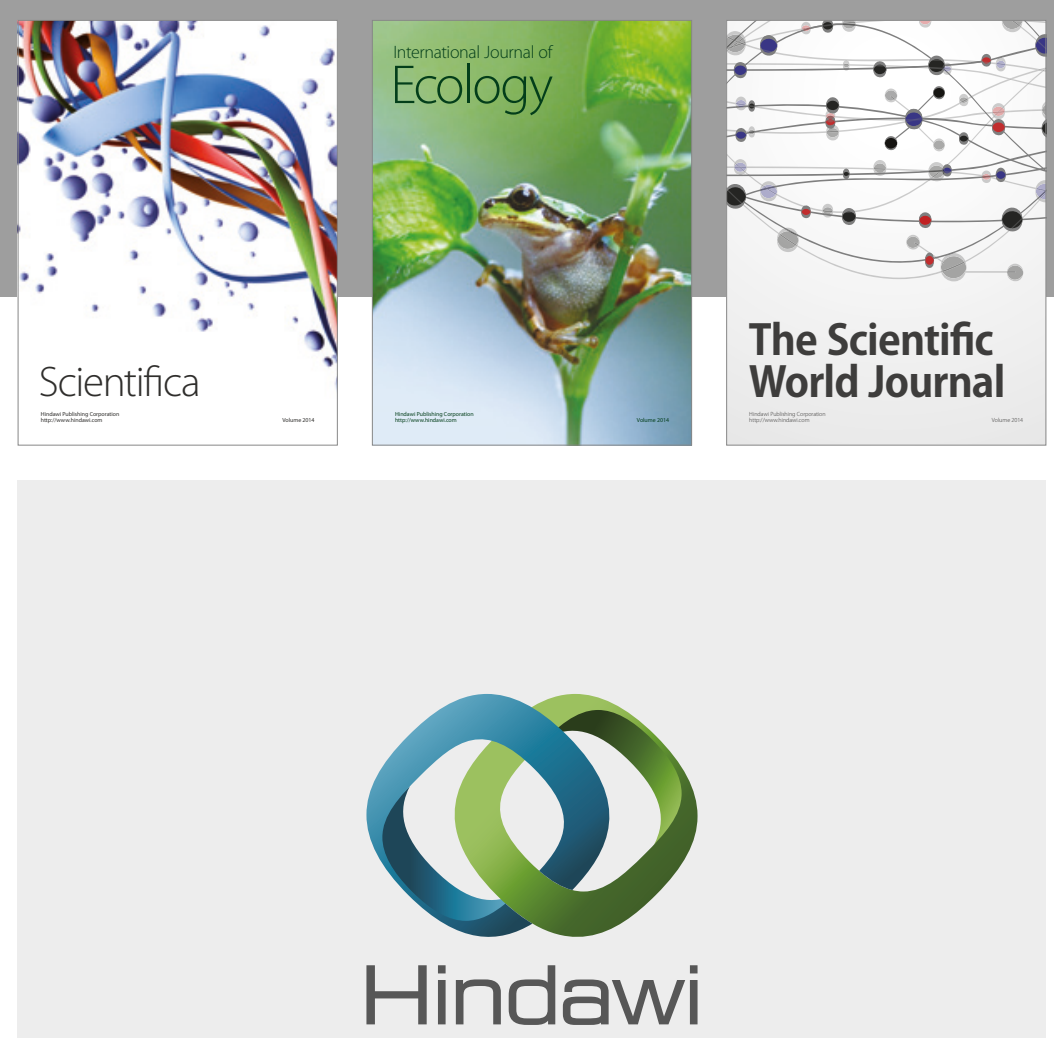

Submit your manuscripts at

https://www.hindawi.com
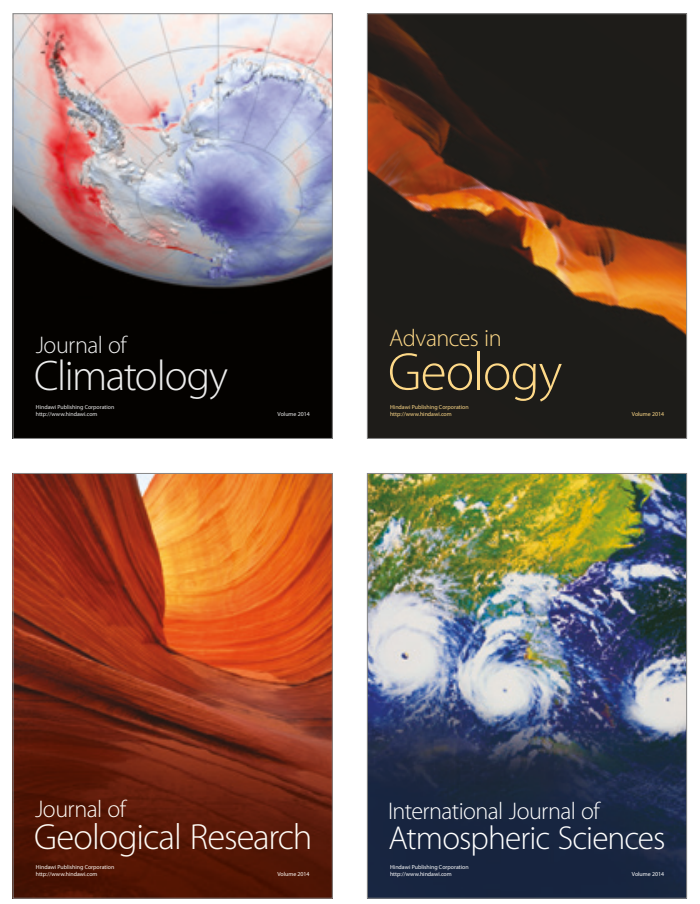

The Scientific

World Journal
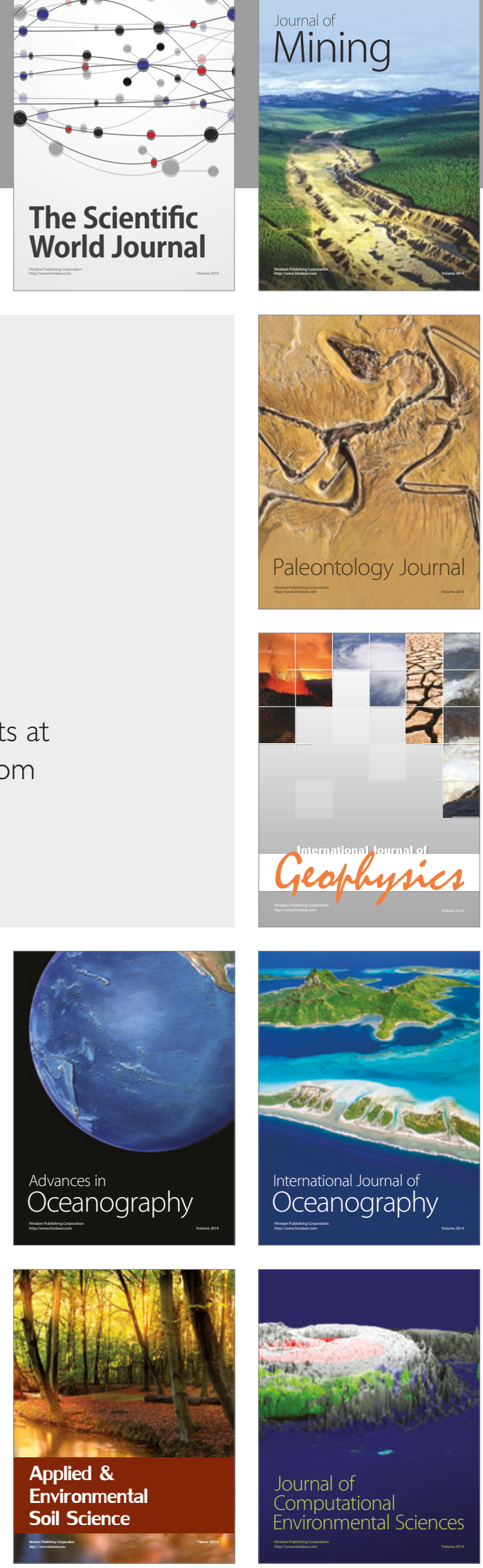